\title{
Surgical Complications in Early Post-transplant Kidney Recipients
}

\author{
H. Pinto ${ }^{a, \star}$, R. Leal ${ }^{a}$, L. Rodrigues ${ }^{a}$, L. Santos ${ }^{a}$, C. Romãozinho ${ }^{a}$, F. Macário ${ }^{a}$, R. Alves ${ }^{a}$, C. Bastos ${ }^{b}$, \\ A. Roseiro ${ }^{\mathrm{b}}$, F. Costa ${ }^{\mathrm{a}}$, M. Campos ${ }^{\mathrm{a}}, \mathrm{A}$. Mota ${ }^{\mathrm{b}}$, and A. Figueiredo ${ }^{\mathrm{b}}$
}

${ }^{a}$ Nephrology Department, Centro Hospitalar e Universitário de Coimbra, Coimbra, Portugal; and ' Urology and Renal Transplantation Department, Centro Hospitalar e Universitário de Coimbra, Coimbra, Portugal

\begin{abstract}
Background. The purpose of this study was to determine the incidence of early surgical complications of kidney transplantation in our institution and its association with donor and recipient factors, as well as patient and transplant outcome.

Methods. A retrospective cohort study of all kidney transplants performed during 2015 was made. We evaluated the incidence of surgical complications and the outcome of patients and grafts at a 3-month follow-up interval.

Results. During the study period, 141 kidney transplants occurred. Seventeen patients had surgical complications (6 urologic, 6 vascular, and 5 other complications). Five patients lost the graft during the follow-up. Older age was associated with other surgical complications $(P=.023)$, and graft loss was associated with the existence of surgical complications, namely, vascular complications $(P<.001)$. For both surgical complications in general and urologic complications, a statistically significant relationship was found with patient weight $(P=.003$ and $P=.034$, respectively). The correlation between body mass index (BMI) and surgical complications was not statistically significant.

Conclusions. Our study reveals that older and heavier patients have a higher risk of surgical complications and that vascular complications are associated with graft loss. A statistically significant relationship was not found between BMI and surgical complications, which could indicate that BMI is not the ideal obesity marker. The incidence of surgical complications found in our study is similar to the literature. The selection of transplant recipients is a difficult task, and the possibility of additional surgical complications in older and overweight patients should be taken into account.
\end{abstract}

$\mathbf{S}$ URGICAL complications in kidney transplant have been decreasing in the past decades, mainly because of improvements in the technical procedure. However, increasing donor and recipient age, recipients with multiple co-morbidities, and the use of potent immunosuppressive drugs can invert this tendency. These complications are associated with increased morbidity, mortality, hospitalization rate, and costs [1-3].

\section{METHODS}

A retrospective cohort study was made, including all kidney transplants performed between January 1 and December 31, 2015. During this period, 141 patients received a kidney transplant, 6 from a living donor and 135 from a cadaveric donor. The mean age at the surgery was $50.3 \pm 13.2$ years. The majority of recipients were male $(71 \%, \mathrm{n}=100)$.
Data related to the kidney transplant and the first 3 months of follow-up in our institution were collected from the clinical files of all the 141 patients. All surgical complications, their nature, and treatment were registered. The outcomes of patients and grafts were evaluated at a 3-month follow-up interval.

Statistical analysis was performed by use of SPSS software. Variables normality was accessed with the use of the KolmogorovSmirnov test. Univariate comparisons were performed with the use of the non-paired Student $t$ test or Mann-Whitney test for continuous variables according to their normality, and the $\chi^{2}$ test was used for categorical variables.

*Address correspondence to Helena Pinto, Centro Hospitalar e Universitário de Coimbra, Praceta Prof. Mota Pinto, 3000-075 Coimbra, Portugal. E-mail: helenasofiapinto@gmail.com

$0041-1345 / 17$

http://dx.doi.org/10.1016/j.transproceed.2017.03.010 


\section{RESULTS}

From the 141 patients studied, 17 had surgical complications in the first 3-month follow-up. The main characteristics of these patients are summarized in Table 1. The majority of these complications were urologic and vascular (Table 2). From this group of patients, 5 lost the graft during the follow-up, 4 because of surgical complications (vascular) and 1 because of infection. No deaths occurred.

Urologic complications occurred in 6 patients $(4.2 \%)$. There were 3 urinary fistulas $(2.1 \%)$, which were treated with surgical revision, in 1 case with the additional use of biological glue, and, in another case, by performance of an ureteroureterostomy to the ipsilateral native ureter. Ureteric stenosis occurred in 3 patients $(2.1 \%)$, in 1 case managed initially with nephrostomy insertion, although all 3 cases ended with ureteric re-implantation.

There were 6 cases of vascular complications (4.2\%). In 1 patient, an arterial thrombosis was verified during the

Table 1. Patient Characteristics

\begin{tabular}{|c|c|c|}
\hline Patient Characteristics & $\begin{array}{l}\text { With Surgical } \\
\text { Complication }\end{array}$ & $\begin{array}{l}\text { Without } \\
\text { Surgical } \\
\text { Complication }\end{array}$ \\
\hline $\begin{array}{l}\text { Age, years, mean; standard } \\
\text { deviation }\end{array}$ & $50.9 ; 11.4$ & $50.2 ; 13.5$ \\
\hline \multicolumn{3}{|l|}{ Sex } \\
\hline Male, n; \% & $13 ; 76.5$ & $87 ; 70.2$ \\
\hline Female, n; \% & $4 ; 23.5$ & $37 ; 29.8$ \\
\hline $\begin{array}{l}\text { Time on dialysis, months, mean; } \\
\text { standard deviation }\end{array}$ & $48.8 ; 39.1$ & $46.2 ; 26.5$ \\
\hline \multicolumn{3}{|l|}{ Original disease } \\
\hline Cause unknown, n; \% & $4 ; 23.6$ & $41 ; 33.1$ \\
\hline Diabetic nephropathy, n; \% & $2 ; 11.8$ & $9 ; 7.3$ \\
\hline $\begin{array}{l}\text { Pyelonephritis or interstitial } \\
\text { nephritis, n; \% }\end{array}$ & $3 ; 17.6$ & $19 ; 15.2$ \\
\hline Glomerulonephritis, n; \% & $5 ; 29.4$ & $25 ; 20.2$ \\
\hline Other, n; \% & $3 ; 17.6$ & $30 ; 24.2$ \\
\hline Diabetes, n; \% & $4 ; 23.5 \%$ & $13 ; 10.5$ \\
\hline $\begin{array}{l}\text { Weight, kg, mean; standard } \\
\text { deviation }\end{array}$ & $79.8 ; 11.7$ & $69.6 ; 12.7$ \\
\hline $\begin{array}{l}\mathrm{BMI}, \mathrm{kg} / \mathrm{m}^{2} \text {, mean; standard } \\
\text { deviation }\end{array}$ & $26.7 ; 3.7$ & $24.9 ; 3.8$ \\
\hline \multicolumn{3}{|l|}{ Donor source } \\
\hline Live, n; \% & $1 ; 5.9$ & $5 ; 4$ \\
\hline Cadaveric, n; \% & $16 ; 94.1$ & $119 ; 96$ \\
\hline $\begin{array}{l}\text { Mismatches, mean; standard } \\
\text { deviation }\end{array}$ & $3.8 ; 1.3$ & $3.9 ; 1.2$ \\
\hline \multicolumn{3}{|l|}{ Kidney original site } \\
\hline Left, n; \% & $10 ; 58.8$ & $60 ; 48.4$ \\
\hline Right, n; \% & $7 ; 41.2$ & $64 ; 51.6$ \\
\hline \multicolumn{3}{|l|}{ Arterial anastomosis } \\
\hline Common iliac artery, $\mathrm{n} ; \%$ & $7 ; 41.2$ & $69 ; 55.6$ \\
\hline External iliac artery, n; \% & $10 ; 58.8$ & $55 ; 44.4$ \\
\hline \multicolumn{3}{|l|}{ Venous anastomosis } \\
\hline Common iliac vein, n; \% & $9 ; 52.9$ & $66 ; 53.2$ \\
\hline External iliac vein, $n ; \%$ & $8 ; 47.1$ & $58 ; 46.8$ \\
\hline \multicolumn{3}{|l|}{ Ureteral anastomosis technique } \\
\hline Lich-Gregoir, n; \% & $13 ; 76.5$ & $92 ; 74.2$ \\
\hline Other-mainly Taguchi, n; \% & $4 ; 23.5$ & $32 ; 25.8$ \\
\hline
\end{tabular}

Table 2. Surgical Complications

\begin{tabular}{llc}
\hline \multicolumn{1}{c}{ Surgical Complication } & $\mathrm{n}$ & Percentage \\
\hline Urologic & & \\
$\quad$ Urinary fistulas & 3 & 2.1 \\
$\quad$ Ureteric stenosis & 3 & 2.1 \\
Vascular & & \\
$\quad$ Arterial thrombosis & 2 & 1.4 \\
Arterial dissection & 2 & 1.4 \\
$\quad$ Venous thrombosis & 1 & 0.7 \\
$\quad$ Arterial stenosis & 1 & 0.7 \\
Other & & \\
$\quad$ Wound dehiscence & 3 & 2.1 \\
$\quad$ Hematoma & 1 & 0.7 \\
$\quad$ latrogenic small-bowel rupture & 1 & 0.7 \\
\hline
\end{tabular}

transplant, with the surgical revision of the anastomosis, but the thrombosis recurred later in the first day with a new attempt to make an anastomosis revision that ultimately failed. In the second patient with arterial thrombosis, the surgical revision was also not successful and in both cases led to a transplantectomy $(1.4 \%)$. In 1 patient, a venous thrombosis occurred $(0.7 \%)$, with posterior transplantectomy. There were 2 cases of arterial dissection $(1.4 \%)$, in both of them with surgical revision and patch placement, although 1 also ended in transplantectomy. In 1 patient, an arterial stenosis was diagnosed $(0.7 \%)$ and stent angioplasty was required.

In 5 patients, other complications occurred $(3.5 \%)$. In this group, 3 wound dehiscences were accounted (2.1\%), but only 1 required re-suturing. There was 1 case of hematoma $(0.7 \%)$ managed with conservative treatment and an iatrogenic small bowel rupture $(0.7 \%)$ that was promptly resolved with primary suture during transplant surgery, followed by an uneventful recovery. No cases of lymphocele, abscess, or incisional hernia occurred.

Older age was significantly associated with other surgical complications $(P=.023)$, and patient weight was associated with surgical complications in general and urologic complications $(P=.003$ and $P=.034$, respectively). Surgical complications, specifically vascular ones, were associated with graft loss $(P<.001)$. A marked tendency was found between higher body mass index (BMI) and surgical complications, although it did not attain a statistically significant relationship. There were no statistically significant differences with cadaveric versus living donors, neither with normal or expanded-criteria donor. In our department, the majority of transplant ureteral anastomosis is made with extravesical Lich-Gregoir technique with an anti-reflux mechanism. No significant difference was found regarding urologic complications with the use of this technique or other techniques (mostly Taguchi).

\section{DISCUSSION}

Kidney transplantation is accepted to be the best treatment modality for patients with end-stage renal disease. However, the surgical complications are still a significant cause of 
morbidity, and, in some cases, result in graft loss. Surgical complications can be divided into early ones, which are the most common and occur during the first 3 months after transplant, and late ones, which refer to the complications that occur after this period. Our rate of surgical complications $(11.9 \%)$ was similar to the ones reported in the literature $(10 \%$ to $25 \%)[4,5]$.

The incidence of urologic complications in our series (4.2\%) was comparable to other studies $(2.5 \%$ to $15 \%)$ $[1-3,6,7]$. Ureteral stenosis and fistula remain the most frequent urologic complications in our department [2]. In our study, the technique of ureteral anastomosis did not influence the incidence of urologic complications. This was already seen in previous studies in our department [8].

Vascular complications occur in $1 \%$ to $23 \%$ of patients according to the literature, and they remain an important cause of graft loss, as demonstrated by our results [9-11].

In our study, older age was associated with other surgical complications. Increased surgical complications in older recipients have been found in other series, but this potential risk is generally outweighed by the benefits of the transplant versus staying in dialysis. However, the risks and benefits should be carefully balanced during pre-transplant evaluation [12].

In our study, BMI was not a statistically important factor to any surgical complications. However, a statistically significant relationship was found with patient weight and both surgical complications in general and urologic complications. There is no consensus in the literature, but recent reviews show that BMI has no significant impact on major surgical complications or graft outcomes [13-16]. These results can emphasize the idea that BMI, as a metric of body fat index, may not be the ideal marker, and that pretransplant evaluation should include other obesity markers such as abdominal circumference.

\section{CONCLUSIONS}

Our results about early surgical complications in kidney transplant recipients are similar to the current literature. Our study suggests that older and heavier patients can have a higher risk of surgical complications and that these factors should be taken into account during their evaluation, balancing the benefit of the transplant versus dialysis. BMI was not a statistically important factor for surgical complications. Vascular complications, as already demonstrated in other studies, are the most feared surgical complications, because they frequently lead to graft loss.

\section{REFERENCES}

[1] Di Carlo HN, Darras FS. Urologic considerations and complications in kidney transplant recipients. Adv Chronic Kidney Dis 2015;22:306-11.

[2] Eufrasio P, Parada B, Moreira P, et al. Surgical complications in 2000 renal transplants. Transplant Proc 2011;43:142-4.

[3] Humar A, Matas AJ. Surgical complications after kidney transplantation. Semin Dial 2005;18:505-10.

[4] Dinckan A, Tekin A, Turkyilmaz S, et al. Early and late urological complications corrected surgically following renal transplantation. Transpl Int 2007;20:702-7.

[5] Kamali K, Zargar MA, Zargar H. Early common surgical complications in 1500 kidney transplantations. Transplant Proc 2003;35:2655-6.

[6] Kocak T, Nane I, Ander H, et al. Urological and surgical complications in 362 consecutive living related donor kidney transplantations. Urol Int 2004:72:252-6.

[7] Streeter EH, Little DM, Cranston DW, Morris PJ. The urological complications of renal transplantation: a series of 1535 patients. BJU Int 2002;90:627-34.

[8] Moreira P, Parada B, Figueiredo A, et al. Comparative study between two techniques of ureteroneocystostomy: Taguchi and Lich-Gregoir. Transplant Proc 2007;39:2480-2.

[9] Ammi M, Daligault M, Sayegh J, et al. Evaluation of the vascular surgical complications of renal transplantation. Ann Vasc Surg 2016;33:23-30.

[10] Fervenza FC, Lafayette RA, Alfrey EJ, Petersen J. Renal artery stenosis in kidney transplants. Am J Kidney Dis 1998;31: $142-8$.

[11] Salehipour M, Salahi H, Jalaeian H, et al. Vascular complications following 1500 consecutive living and cadaveric donor renal transplantations: a single center study. Saudi J Kidney Dis Transpl 2009;20:570-2.

[12] Singh P, Ng YH, Unruh M. Kidney transplantation among the elderly: challenges and opportunities to improve outcomes. Adv Chronic Kidney Dis 2016;23:44-50.

[13] Tremblay S, Kaiser TE, Alloway RR, et al. Absence of the effect of pretransplant body mass index on post kidney transplant outcomes. Prog Transplant 2016;26:183-90.

[14] Furriel F, Parada B, Campos L, et al. Pretransplantation overweight and obesity: does it really affect kidney transplantation outcomes? Transplant Proc 2011;43:95-9.

[15] Tran MH, Foster CE, Kalantar-Zadeh K, Ichii H. Kidney transplantation in obese patients. World J Transplant 2016;6: $135-43$.

[16] Hill CJ, Courtney AE, Cardwell CR, et al. Recipient obesity and outcomes after kidney transplantation: a systematic review and meta-analysis. Nephrol Dial Transplant 2015;30:1403-11. 